\title{
Nanoscale Confinement and Fluorescence Effects of Bacterial Light Harvesting Complex LH2 in Mesoporous Silicas
}

Ikemoto, Hideki; Tubasum, Sumera; Pullerits, Tonu; Ulstrup, Jens; Chi, Qijin

Published in:

The Journal of Physical Chemistry Part C

Link to article, DOI:

10.1021/jp311239y

Publication date:

2013

Document Version

Publisher's PDF, also known as Version of record

Link back to DTU Orbit

Citation (APA):

Ikemoto, H., Tubasum, S., Pullerits, T., Ulstrup, J., \& Chi, Q. (2013). Nanoscale Confinement and Fluorescence Effects of Bacterial Light Harvesting Complex LH2 in Mesoporous Silicas. The Journal of Physical Chemistry Part C, 117(6), 2868-2878. https://doi.org/10.1021/jp311239y

\section{General rights}

Copyright and moral rights for the publications made accessible in the public portal are retained by the authors and/or other copyright owners and it is a condition of accessing publications that users recognise and abide by the legal requirements associated with these rights.

- Users may download and print one copy of any publication from the public portal for the purpose of private study or research.

- You may not further distribute the material or use it for any profit-making activity or commercial gain

- You may freely distribute the URL identifying the publication in the public portal 


\title{
Nanoscale Confinement and Fluorescence Effects of Bacterial Light Harvesting Complex LH2 in Mesoporous Silicas
}

\author{
Hideki Ikemoto, ${ }^{\dagger \neq}$ Sumera Tubasum, ${ }^{\dagger, \S}$ Tönu Pullerits, ${ }^{*}, \S$ Jens Ulstrup, ${ }^{\ddagger}$ and Qijin Chi* ${ }^{*} \ddagger$ \\ ${ }^{\ddagger}$ Department of Chemistry and NanoDTU, Technical University of Denmark, DK-2800 Kgs. Lyngby, Denmark \\ ${ }^{\S}$ Department of Chemical Physics, Lund University, Sweden
}

\section{Supporting Information}

ABSTRACT: Many key chemical and biochemical reactions, particularly in living cells, take place in confined space at the mesoscopic scale. Toward understanding of physicochemical nature of biomacromolecules confined in nanoscale space, in this work we have elucidated fluorescence effects of a light harvesting complex LH2 in nanoscale chemical environments. Mesoporous silicas (SBA-15 family) with different shapes and pore sizes were synthesized and used to create nanoscale biomimetic environments for molecular confinement of LH2. A

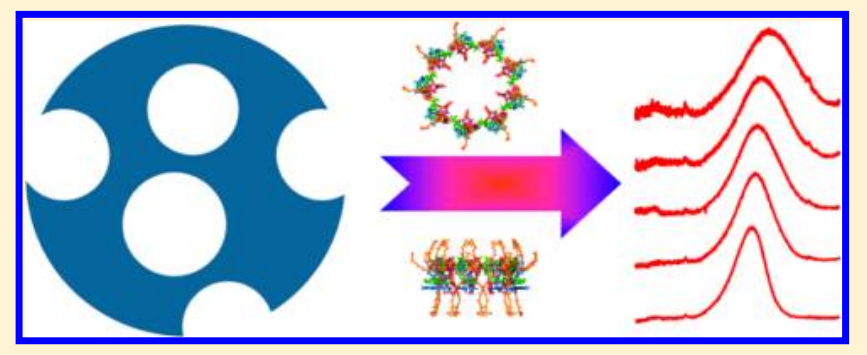
combination of UV-vis absorption, wide-field fluorescence microscopy, and in situ ellipsometry supports that the LH2 complexes are located inside the silica nanopores. Systematic fluorescence effects were observed and depend on degree of space confinement. In particular, the temperature dependence of the steady-state fluorescence spectra was analyzed in detail using condensed matter band shape theories. Systematic electronicvibrational coupling differences in the $\mathrm{LH} 2$ transitions between the free and confined states are found, most likely responsible for the fluorescence effects experimentally observed.

\section{INTRODUCTION}

Many biochemical reactions in living cells take place in confined space at the mesoscopic scale. ${ }^{1}$ The impact of mesoscopic phenomena in biological science and technology has recently been overviewed by Kalay. ${ }^{2}$ Structural and functional characterization of biomolecules and/or their ensembles confined in specific nanoscale environments could offer new clues to fundamental understanding of complex biological events, where the use of mesoporous materials has emerged as a powerful tool. According to the IUPAC definition, mesoporous materials are materials that possess nanometer pores in the size range of $2-50 \mathrm{~nm} .^{3}$ This size range matches the dimension of different biological entities such as proteins, cell membranes, and lipids. Mesoporous materials can thus serve as favorable hosts that provide nanoscale environments for confinement of biomolecules for various purposes. A recent report has shown a further unique advantage of mesoporous materials in studying biological macromolecules at cryogenic temperatures, as nanopore-confined water remains in a liquid state even at subfreezing temperatures. ${ }^{4}$

The remarkable progress in the development of mesoporous silica materials was initiated with the synthesis of MCM-41 first reported in 1992..$^{5}$ Different types of mesoporous silicas have since then been designed and prepared, ${ }^{6-8}$ among which Santa Barbara Amorphous-15 (SBA-15) 9 and mesocellular silica foam (MCF) families ${ }^{10}$ are of particular interest. The application of mesoporous silicas in biomolecular systems was pioneered by Diaz and Balkus in 1996, who introduced MCM-41 to encapsulate a relatively small redox protein, cytochrome c. ${ }^{11}$
This research line has been rapidly expanded to immobilization of various enzymes for catalysis and biosensors. ${ }^{12}$ Since the successful synthesis of mesoporous silicas with larger pore sizes (e.g., 5-30 nm) represented by the SBA-15 family in late 1990s, pioneered by Zhao et al., ${ }^{9}$ it has become feasible to accommodate larger biomolecules or biomolecular ensembles. As a consequence, the applications of mesoporous silicas in biological science and technology have been promoted tremendously. A number of areas have benefited from this progress, for example enzyme immobilization, ${ }^{12,13}$ drug delivery, ${ }^{14}$ and biosensing devices. ${ }^{15}$ More recently, the application has been extended to more complex or fragile biological systems such as protein complexes in proteomics, ${ }^{16}$ fragile RNase, ${ }^{17}$ and photosynthetic components. ${ }^{18-21}$

Photosynthesis arguably represents the ultimate source of energy needed for activities on Earth, achieved in nature by structurally complex but highly refined molecular apparatus. $^{22,23}$ The two essential components of this apparatus are the light harvesting antennas (LHs) and the reaction centers (RC). The LHs are responsible mainly for gathering and transferring radiation energy to the RC where charge separation takes place. ${ }^{24}$ In a natural molecular architecture, most of the LHs and all RCs are confined in lipid membranes. In photosynthetic purple bacteria the RC is surrounded by a so-called core antenna LH1, whereas the peripheral antenna $\mathrm{LH} 2$ is in contact

Received: November 13, 2012

Revised: January 16, 2013

Published: January 17, 2013 
with $\mathrm{LH} 1 .^{17}$ In vitro studies of photosynthetic reactions have been of long-standing interest driven by an urge both for fundamental understanding of mechanisms and for applications in design and fabrication of solar energy devices. Ultrafast, highresolution, and multidimensional spectroscopies are among the most efficient means for gaining details of such complicated reactions. $^{25-35}$

In a recent effort, a LH2 complex from Thermochromatium tepidum was immobilized on folded-sheet mesoporous silicas (FSM), and the studies were focused on photoinduced electron transfer (ET) ${ }^{20}$ However, the FSM material used has a pore size of about $7.9 \mathrm{~nm}$, which is smaller than the molecular dimensions of $\mathrm{LH} 2$. There was no direct evidence that $\mathrm{LH} 2$ was confined inside the nanopores. Most likely, the LH2 complex was adsorbed only on the FSM particle surfaces due to inappropriate pore size. In the present work, SBA-15 silica with hexagonally ordered cylindrical pores and mesocellular foam (MCF) type mesoporous silica with less ordered cagelike mesopores were synthesized and used as hosts to provide a biomimetic environment for nanoscale confinement of $\mathrm{LH} 2$ from Rps. acidophila. The fluorescence spectra of free dissolved and nanopore confined LH2 were compared and analyzed, enabling us to examine the effects of limited space and local environments on the photophysical properties of $\mathrm{LH} 2$.

\section{MATERIALS AND METHODS}

2.1. Chemicals and Materials. Tetraethyl orthosilicate (98\% (GC), Aldrich), poly(ethylene glycol)-block-poly(propylene glycol)-block-poly(ethylene glycol) (denoted as Pluronic P-123, Sigma-Aldrich), Trisma base (Primary Standard and Buffer, $\geq 99.9 \%$ ), and $N, N$-dimethyldodecylamine $\mathrm{N}$ oxide solution (lauryl dimethylamine $\mathrm{N}$-oxide (LDAO), 30\% solution, Sigma-Aldrich) were used as received. The LH2 samples isolated from Rps. acidophila or Rhodobacter ( $R b$.) sphareoides were prepared as described previously ${ }^{36}$ and stored at low temperatures $\left(-20{ }^{\circ} \mathrm{C}\right)$. Other agents used were at least of analytical grade. Milli-Q water $(18.2 \mathrm{M} \Omega \mathrm{cm})$ was used throughout.

2.2. Synthesis of Silica Particles. Mesoporous silica materials including rod-shaped SBA-15 (SBA-rod), spherical SBA-15 particles with larger pores (SBA-sph-1), and spherical SBA-15 particles with smaller pores (SBA-sph-s) were synthesized according to the previous procedures with modifications. ${ }^{37-39}$ The experimental details are provided in the Supporting Information.

2.3. Characterization of Silica Particles. The synthesized mesoporous silicas were systematically characterized by a number of techniques including powder X-ray diffraction (XRD), transmission electron microscopy (TEM), scanning electron microscopy (SEM), and nitrogen adsorptiondesorption to obtain physical and structural characteristics of the materials. The procedures and instrumental methods, together with the supporting data are detailed in the Supporting Information.

2.4. Trapping of $\mathrm{LH} 2$ in Mesoporous Silicas. In a typical preparation, $7 \mu \mathrm{L} \mathrm{LH} 2$ from a stock solution was diluted using $2.5 \mathrm{~mL}$ Tris buffer $(25 \mathrm{mM}, \mathrm{pH} 8.5)$ containing $0.1 \%$ LDAO. One milliliter of the resultant $\mathrm{LH} 2$ solution was mixed with 1 mg silica particles, stirred at $4{ }^{\circ} \mathrm{C}$ for $3-3.5 \mathrm{~h}$, and centrifuged. The supernatant was then mixed with $1 \mathrm{mg}$ fresh silica particles again, followed by stirring at $4{ }^{\circ} \mathrm{C}$ for $3-3.5 \mathrm{~h}$ and centrifugation. The LH2-SBA-15 conjugates were washed with Tris buffer and resuspended in $25 \mathrm{mM}$ Tris buffer $(\mathrm{pH}$
8.5). The absorbance of the solution was measured with a UVvis spectrophotometer (HP8453, Hewlett-Packard).

2.5. Fluorescence Spectroscopy at Low Temperatures. In a typical procedure, a few drops of free LH2 solution or LH2-silica particle suspended solution were deposited onto a glass slide and dried at room temperature. Figure S8 of the Supporting Information compares the schematic setups used in fluorescence measurements at room temperature and low temperatures. The fluorescence emission was detected with a $\mathrm{N}_{2}$-cooled CCD detector (HORIBA Jobin Yvon). The sample was excited at $800 \mathrm{~nm}$ with a Continuous Wave (CW) Ti:Sapphire laser (Spectra Physics Model 3900S) and cooled by liquid nitrogen in a Janis STVP-400 cryostat. The temperature was controlled by a temperature controller (Lake Shore 331). The experimental setup is shown in Figure S9 of the Supporting Information. The spectra obtained were corrected for the wavelength dependent sensitivity of the detector. The fluorescence spectra, $I(\lambda)$, were converted to wavenumber scale as $I(\tilde{\nu})=\lambda^{2} I(\lambda)$ and weighted by $\tilde{\nu}^{-3}{ }^{40}$ This representation was used to extract electronic transition energies and related parameters. ${ }^{41}$

2.6. Wide-Field Fluorescence Microscopy. The sample was prepared by depositing a drop of $\mathrm{LH} 2$ solution or suspension of LH2-SBA-15 conjugate on a cover glass and dried by spin-coating. Fluorescence microscopy was performed using an oil immersion objective lens. Dinitrogen was supplied over the cover glass to prevent photobleaching. The sample was excited at $800 \mathrm{~nm}$ with a CW laser. Images were recorded with a CCD camera (PhotonMax). The layout for fluorescence microscopy is shown in Figure S10 of the Supporting Information.

2.7. Lifetime Measurements. The same setup as for widefield microscopy (Figure S10 of the Supporting Information) was used. The samples were excited at $458 \mathrm{~nm}$ using a pulsed laser. Emitted light was detected by an avalanche photodiode (APD) and signal from APD was counted by PicoHarp 300. All of the decay curves were fitted with MATLAB.

2.8. Ellipsometry Measurments. The adsorption of $\mathrm{LH} 2$ on the surface of a flat silica substrate was monitored by an automated Rudolph thin film ellipsometer, type 43603-200E, equipped with a thermostat. The silica surface was prepared as described previously. ${ }^{42}$ Briefly, silicon wafers were cut into slides with a width of $12.5 \mathrm{~mm}$. These slides were cleaned by immersion for $5 \mathrm{~min}$ at $80{ }^{\circ} \mathrm{C}$ first in $\mathrm{NH}_{3}: \mathrm{H}_{2} \mathrm{O}_{2}: \mathrm{H}_{2} \mathrm{O}(1: 1: 5)$ $(\mathrm{v} / \mathrm{v} / \mathrm{v})$ and then in $\mathrm{HCl} / \mathrm{H}_{2} \mathrm{O}_{2} / \mathrm{H}_{2} \mathrm{O}(1: 1: 5)$ (v/v/v). They were then treated with hydrofluoric acid and rinsed with distilled water. The cleaned wafers were then oxidized thermally at $920{ }^{\circ} \mathrm{C}$ in oxygen atmosphere for $27 \mathrm{~min}$. This procedure gives an oxide layer with a thickness in the range of 300 to $350 \AA$.

The adsorption experiments were performed using $3 \mathrm{~mL}$ of $25 \mathrm{mM}$ Tris buffer $(\mathrm{pH}$ 8.5) in a cuvette while stirring at around $100 \mathrm{rpm}$. The temperature of the cuvette was maintained at $25{ }^{\circ} \mathrm{C}$. For adsorption experiment of a mixture of $\mathrm{LH} 2$ and $\mathrm{LDAO}$, a stock solution of the mixture of $\mathrm{LH} 2$ and LDAO was prepared $(0.64 \mathrm{mg} / \mathrm{mL} \mathrm{LH} 2$ and $1 \% \mathrm{w} / \mathrm{v} \mathrm{LDAO})$. At a given time, a sample of the stock solution was added to the cuvette which contained $3 \mathrm{~mL}$ Tris buffer at the starting point $(t=0)$. The cuvette was rinsed with the buffer at a flow rate of $20 \mathrm{~mL} \mathrm{~min}{ }^{-1}$. The adsorbed amount was calculated using $\mathrm{d} n / \mathrm{d} c$ $=0.15$ (where $n$ is the refractive index of the adsorbed material, and $c$ the concentration). ${ }^{43}$ 


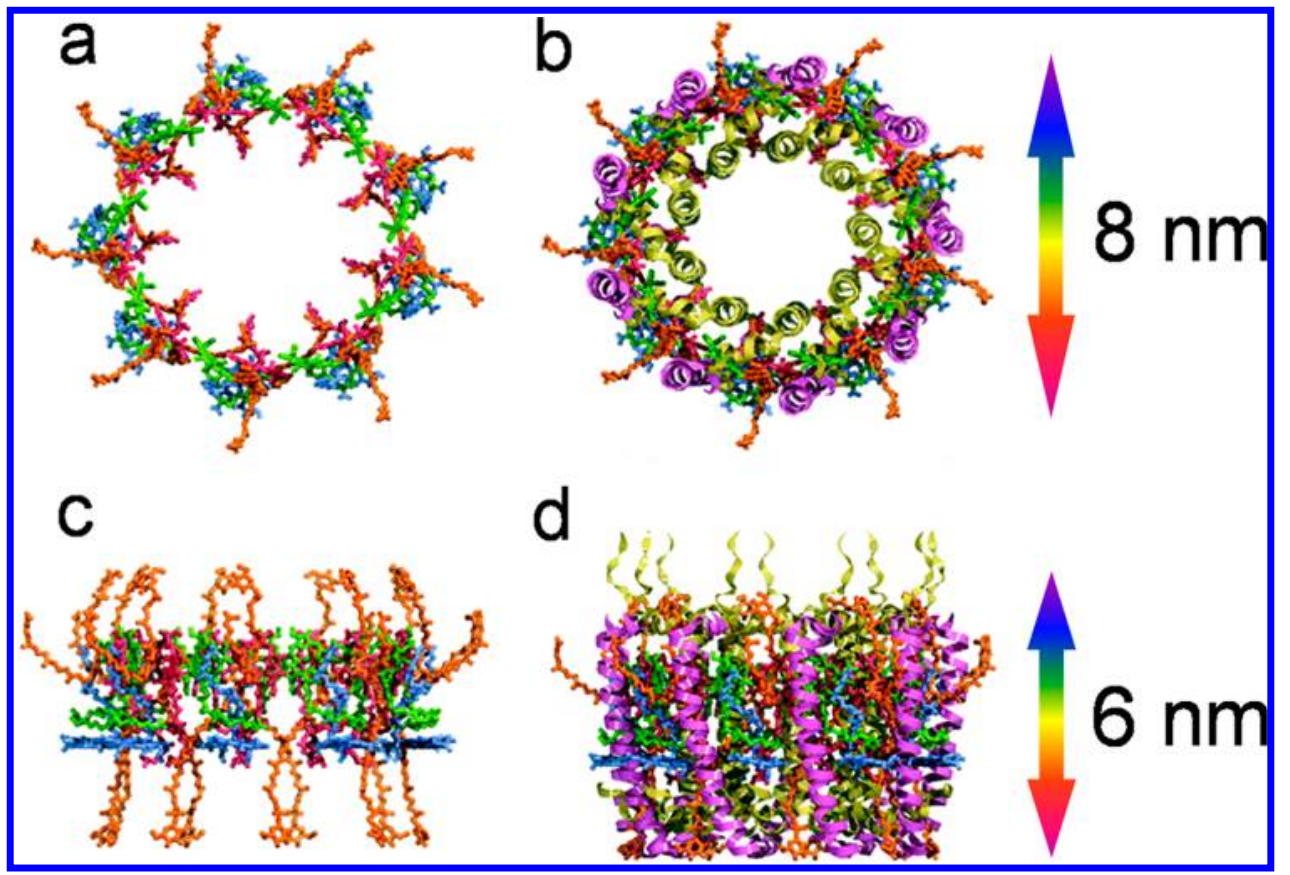

Figure 1. Schematic representations of 3D structure of the LH2 complex: (a,b) top view, and (c,d) side view. The $\alpha$ and $\beta$ polypeptides are drawn as light-green and purple ribbons, respectively. The dimensions of the complex are noted, i.e., about $8 \mathrm{~nm}$ in diameter of the ring and $6 \mathrm{~nm}$ in height. For the detail see ref 47 .

\section{RESULTS AND DISCUSSION}

LH2 from Rps. acidophila was used in this work. Two helices, the so-called $\alpha$ and $\beta$ polypeptides form a heterodimer. Each such module contains three bacteriochlorophylls and one carotenoid molecule. Nine such modules are circularly arranged forming a ring (part a of Figure 1), with the $\alpha$ and $\beta$ polypeptides located inside and outside the ring, respectively (part b of Figure 1). This complex is about $8 \mathrm{~nm}$ in the ring diameter (part b of Figure 1) and $6 \mathrm{~nm}$ in side height (part $\mathrm{d}$ of Figure 1), ${ }^{32}$ which is comparable with the pore sizes of the silicas used in the present work.

We first briefly summarize the physical and structural characteristics of the mesoporous silicas used, followed by the preparation of LH2-silica conjugates and identification of LH2 location in silica particles. We then present the features of the fluorescence spectra combined with spectral band shape analyses, followed by discussion of these observations and their implications.

3.1. Physical and Structural Characteristics of Synthesized Mesoporous Silicas. As noted, three types of mesoporous silicas were synthesized and systematically characterized. The main results are provided in the Supporting Information. XRD (Figure S1), SEM and TEM (Figures S2 and S3), and dinitrogen adsorption-desorption measurements (Figure S4) have overall disclosed the physical and structural features of the mesoporous silicas, as summarized in Table S1. SBA-rod has a rodlike shape and contains cylindrical pores in ordered hexagonal arrays with an average pore diameter of 9.4 $\mathrm{nm}$. Both SBA-sph-s and SBA-sph-1 have a spherical shape and less ordered pores with the average pore sizes of 3.7 and 17.3 $\mathrm{nm}$, respectively. As noted, SBA-sph-1 has a MCF-like inside microscopic network consisting of large spherical disordered pores (called cells) interconnected by smaller openings (named windows). There are several methods available for determining the pore sizes. The pore diameter of SBA-15 with hexagonal arrays of cylindrical pores was determined by both the nonlocal density functional theory (NLDFT) ${ }^{44}$ and Barrett-JoynerHalenda $(\mathrm{BJH})^{45}$ methods for comparison. Because SBA-sph-1 has a more complicated $3 \mathrm{D}$ pore structure consisting of large spherical cells and smaller windows, the pore sizes were only determined by the $\mathrm{BJH}$ method. However, it is known that the $\mathrm{BJH}$ method could underestimate the pore size by up to about $20 \%{ }^{46}$ This means that the actual pore size of SBA-sph-1 could be between 17 and $20 \mathrm{~nm}$. On the basis of these physical and structural characters, Figure 2 is proposed to illustrate schematically the arrangement and size of the nanopores in two types of silicas.

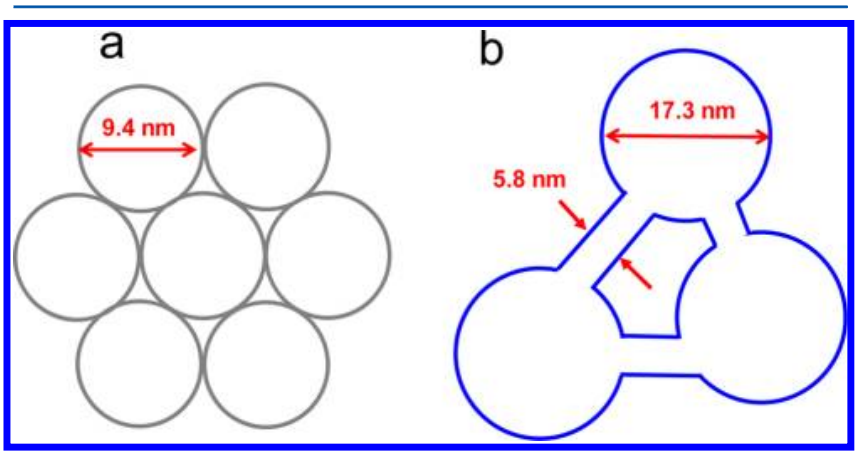

Figure 2. Schematic illustrations of a topographic view of the proposed pore arrangements in (a) SBA-rod and (b) SBA-sph-l silica particles. The SBA-rod has hexagonically ordered pores, while the nanopores in SBA-sph-l are disordered and interconnected by smaller windows. Not drawn to scale.

3.2. Confinement and Location of $\mathrm{LH} 2$ in Mesoporous Silica Particles. Part a of Figure 3 shows a typical UV-vis absorption spectrum of $\mathrm{LH} 2$ at room temperature. The characteristic absorption bands are marked and their physical origin is well documented. ${ }^{47-49}$ The UV-vis absorption was used in monitoring of the accommodation of $\mathrm{LH} 2$ into the mesoporous silicas. To achieve stable encapsulation of $\mathrm{LH} 2$ in 


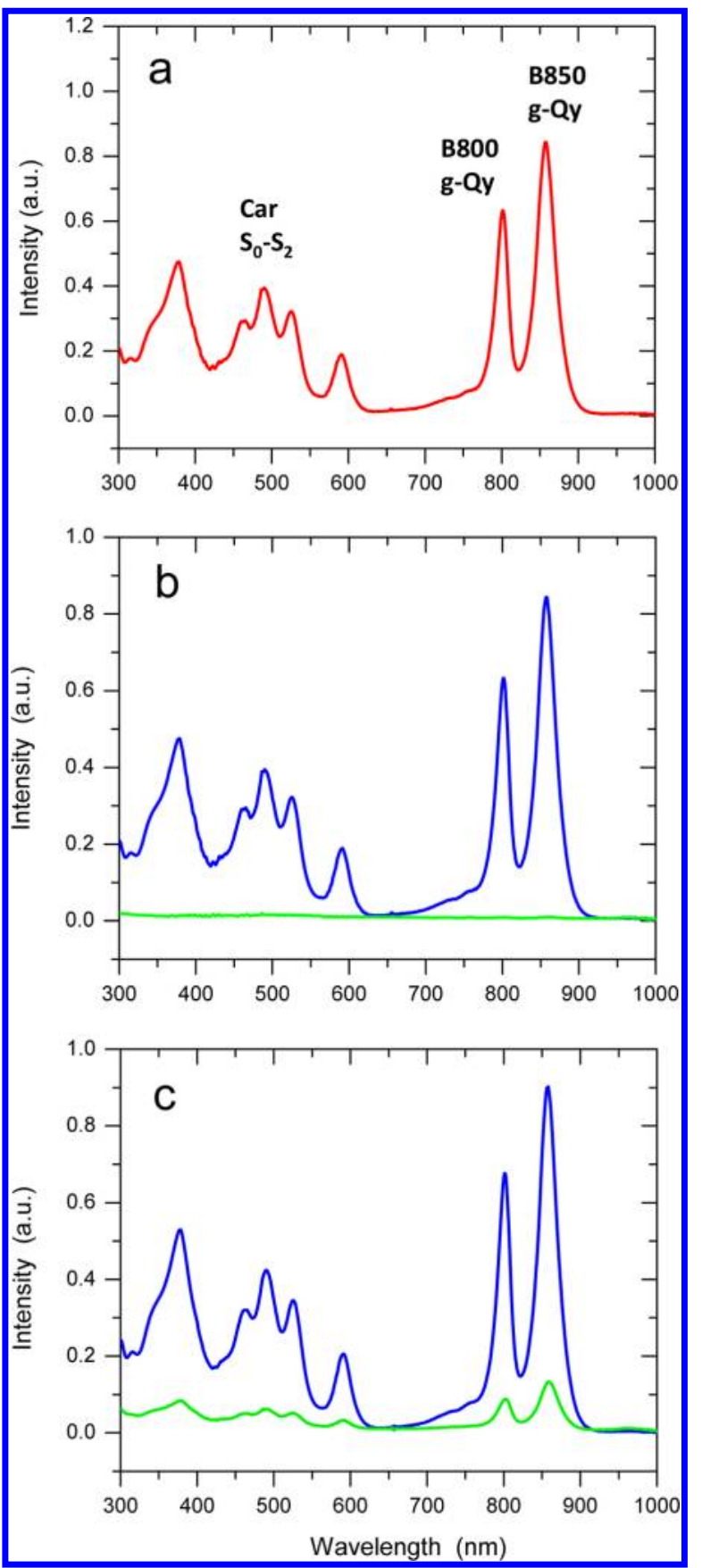

Figure 3. UV-vis absorption spectra of LH2 in buffer solutions ( 25 $\mathrm{mM}$ Tris- $\mathrm{HCl}$ buffer with $0.1 \% \mathrm{LDAO}, \mathrm{pH} 8.5$ ): (a) a representative spectrum with the characteristic bands marked, (b) and (c) monitoring of the preparation of LH2-SBA-rod and LH2-SBA-sph-l conjugates. The blue and green curves are the spectra before and after $3 \mathrm{~h}$ incubation in the second step, respectively.

silicas, it was found that a two-step procedure was needed. LH2 containing Tris buffer with $0.1 \%$ LDAO was incubated with mesoporous silica under stirring for about $3 \mathrm{~h}$. In this first-step incubation, almost no absorption change was observed (Figure S5 of the Supporting Information). This is most likely attributed to blocking of the nanopores by the surfactant LDAO, which prevents $\mathrm{LH} 2$ from entering. In the second step, the supernatant that contains $\mathrm{LH} 2$ obtained from the first step was mixed again with fresh silica particles under stirring for another $3 \mathrm{~h}$. This second incubation resulted in a dramatic decrease in the absorption bands (parts b and $\mathrm{c}$ of Figure 3 ). The observations are similar for SBA-rod (with $9.4 \mathrm{~nm}$ pores) and SBA-sph-1 (with $17 \mathrm{~nm}$ pores). In contrast, the absorption decrease is negligible for SBA-sph-s (3.7 nm pores) (Figure S6 of the Supporting Information). The UV-vis monitoring has thereby shown that trapping of $\mathrm{LH} 2$ in silica particles depends on the pore size indicating that $\mathrm{LH} 2$ is confined inside the pores. The need for involving two steps is most likely associated with detergent molecules preventing adsorption of Lh2 to silica particles in the first step. This is supported by capillary electrophoresis for protein separation, where nonionic or zwitterionic detergents are often used to coat fused-silica capillaries to prevent proteins from attaching to capillary walls. $^{50}$

The location of LH2 in silica particles was further investigated by wide-field fluorescence microscopy. The samples prepared in the absorption experiments were imaged by a fluorescence microscope. As an example, part a of Figure 4 shows the image obtained for LH2-SBA-sph-l conjugates. Silica particles are strongly fluorescent after encapsulation of $\mathrm{LH} 2$ molecules. In the case of SBA-sph-s, however, very few $(<5 \%)$ or no fluorescent particles were found (part b of Figure 4). These observations are consistent with the conclusion drawn from the UV-vis spectra. We also performed the experiments for adsorption of LH2 onto a flat silica substrate, which was monitored in situ by ellipsometry. As shown in Figure S7 and Table S2 of the Supporting Information, physical adsorption of LH2 on the silica surface most likely occurred. However, the adsorption appears to be temporary and unstable. The adsorbed LH2 was thus almost completely removed upon rinsing. The residual amount in Figure S7 of the Supporting Information is due to the adsorption of surfactant LDAO. However, after many attempts we could not obtain highresolution fluorescence microscopy images for LH2-SBA-rod samples. This observation is most likely attributed to the relatively thicker walls in SBA-rod particles, although the exact reason is not completely clear at present.

From the measurements by three experimental techniques (i.e., UV-vis spectrophotometry, fluorescence microscopy, and ellipsometry), we can conclude that $\mathrm{LH} 2$ is located inside the pores of the silica particles rather than being physically adsorbed on the particle surfaces. Schematic illustrations of LH2 in the nanopores are shown in parts $c$ and $d$ of Figure 4 for SBA-sph-1 and SBA-rod, respectively. However, with the fluorescence microscopy resolution at the level of 0.5 to $1 \mu \mathrm{m}$, we are not able to obtain information about organization and distribution of LH2 inside the pores. This is a general and tough challenge remaining. No defined technique is currently available for direct probing of the details concerning the distribution, organization, and $3 \mathrm{D}$ structures of biological macromolecules once they are confined inside the nanoscale pores.

3.3. Kinetics of Time-Resolved Fluorescence Decay. Time-resolved fluorescence spectra at room temperature were recorded and the fluorescence kinetics of free $\mathrm{LH} 2$ and confined LH2 in silica particles are compared.

The lifetime of $\mathrm{LH} 2$ can decrease due to excitation annihilation if the excitation power exceeds a threshold value where more than one excitation can be present in a LH2. ${ }^{51}$ Time-resolved spectra were therefore recorded at an excitation density of $3.2 \times 10^{11}$ photons/(pulse $\mathrm{cm}^{2}$ ) corresponding to 5.6 $\times 10^{-4}$ photons/(pulse.LH2 ring), which is well below the annihilation threshold. ${ }^{52}$ The difference in fluorescence decay 


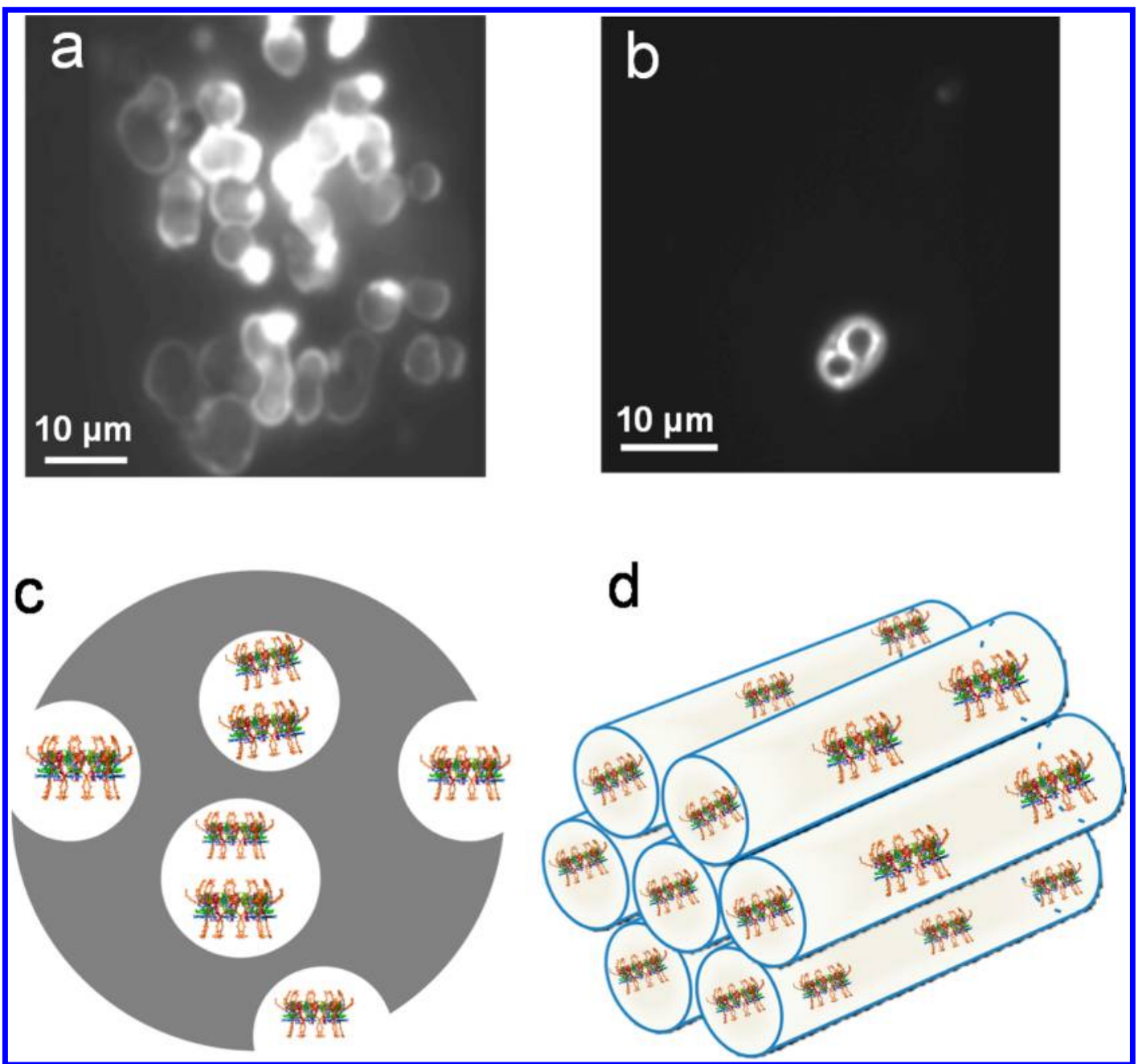

Figure 4. Nanoscale confinement of LH2 in mesoporous silicas characterized by fluorescence microscopy. (a) An image of wide-field fluorescence microscopy for LH2-SBA-sph-l (17.3 nm pores), (b) an image of wide-field fluorescence microscopy for LH2-SBA-sph-s (3.7 nm pores) as a comparison, where extremely few particles exhibit detectable fluorescence $(<5 \%)$, (c) and (d) schematic illustrations of possible locations of LH2 molecules in the nanoscale pores of (c) SBA-sph-1 with disordered pores and (d) SBA-rod with ordered pores. In (c), the gray spheres denote spherical MCF silica particles and the pore is shown in white. Not drawn to scale in (c) and (d).

patterns of LH2 between free and confined states is significant and depends systematically on the local environments. The observed decay for free $\mathrm{LH} 2$ and LH2-SBA-sph-1 can be fitted with a single exponential with a time constant of $1.1 \mathrm{~ns}$ for free LH2 and $0.69 \mathrm{~ns}$ for LH2-SBA-sph-1. In contrast, the fluorescence decay of LH2-SBA-rod displays a clear biexponential dependence with the notably shorter time constants of $\tau_{1}=0.077 \mathrm{~ns}$ and $\tau_{2}=0.39 \mathrm{~ns}$, respectively. Each of the phases in the biexponential behavior may, further envelope a distribution of lifetimes and therefore reflect both more complex kinetics and higher degree of inhomogeneity. The lifetime of free LH2 (1.1 ns) is consistent with that reported for the detergent stabilized LH2 from Rps. acidophila. ${ }^{52}$

The fluorescence lifetime depends on the refractive index approximately as $\tau \sim 1 / \mathrm{n}^{2}$. The refractive index of water and SBA-15 is 1.33 and 1.15 , respectively. ${ }^{53}$ The (singleexponential) lifetime of $\mathrm{LH} 2$ in mesoporous SBA is therefore calculated as ca. $1.47 \mathrm{~ns}$, but the observed lifetime ( $0.69 \mathrm{~ns})$ is notably shorter. Likely reasons are additional fluorescence quenching channels possibly caused by molecules or functional groups such as oxidized $\mathrm{LH} 2$ pigments located inside the pores of silica.
Differences in lifetime patterns between spherical and rod LH2-SBA conjugates are much more pronounced with faster and multiexponential LH2-SBA-rod decay compared with slower and single-exponential LH2-SBA-sph-1 decay. This is most likely due to different organization of $\mathrm{LH} 2$ in the pores and different degrees of space confinement. As noted in section 3.1, SBA-rod has cylindrical pores $(9.4 \mathrm{~nm})$ in an ordered hexagonal array, whereas the SBA-sph-l pores $(17-20 \mathrm{~nm})$ are largely disordered with a foamlike structure. LH2 could therefore be accommodated in the particles in the following way. $\mathrm{LH} 2$ in the LH2-SBA-rod conjugate is located in the ordered cylindrical pores with a high degree of confinement. This can lead to dense packing of LH2 molecules (LH2s) inside the particles. In contrast, LH2 in the LH2-SBA-sph-1 conjugate is located in the disordered pores with a lower degree of confinement and each pore can contain more than a single LH2 complex. This could lead to inhomogeneous distribution and most importantly to less dense packing of LH2s inside the particles, with $\mathrm{LH} 2$ molecules mainly located close to the entrance of the pores. Dense LH2 packing in the SBA-rod particles can lead to efficient energy transfer between LH2 complexes which can drastically reduce the threshold of the 
nonlinear annihilation effects. ${ }^{32}$ As a consequence, the fluorescence lifetime is shortened. The two lifetime components are substantially different possibly indicating two different LH2 aggregation forms in SBA-rod particles. In contrast, the less dense arrangement of $\mathrm{LH} 2$ complexes in SBA-sph-1 particles, which is in a sense closer to free $\mathrm{LH} 2$ in solution, may have led to less efficient intercomplex energy transfer. Further details of the time-resolved fluorescence quenching of pore-confined $\mathrm{LH} 2$ are desirable and will be reported elsewhere. Trapping of large protein molecules in different molecular scale, partly structurally frozen local environments and inhomogeneous distributions of dynamic physical parameters such as excited state lifetimes may have a bearing on photosynthetic dynamics in similar scale membrane confinement. Faster fluorescence decay might lead to a lower yield of the electron transfer processes in the photosynthetic reaction centers. The observed confinement effects could therefore be representative of additional control in the interplay between photosynthetic electronic excitation energy and electron transfer.

3.4. Features of Temperature-Dependent SteadyState Fluorescence Spectra. Steady-state fluorescence spectra were acquired at different temperatures ranging from room temperature $(298 \mathrm{~K})$ to liquid-nitrogen temperature (77 $\mathrm{K})$ for all three types of samples (i.e., free LH2, LH2-SBA-sph1 , and LH2-SBA-rod). Figure 5 compares the fluorescence spectra of the three cases obtained at three different temperatures, and the series of temperature-dependent spectra are shown in Figure 6. The spectral features based on these observations are: (a) at a given temperature, the peak is blueshifted with increasing degree of space confinement (Figure 5), (b) The blue-shift is more profound at low temperatures (parts b and $c$ of Figure 5). (c) The band shape for all three types of samples depends on temperature, with significant narrowing (or decreasing bandwidth) at low temperatures (Figure 6). Further discussion of these changes are given below.

3.5. Bandwidth and Band Shape Analysis of SteadyState Fluorescence Spectra. Theoretical analysis of the spectral features summarized in section 3.4, using both symmetric (Gaussian) and asymmetric fitting functions was also performed ${ }^{54-57}$ with the peak positions, peak widths and asymmetry factors extracted and analyzed. The results are shown in Figures 7 and 8 and are further detailed in Tables S3 and $S 4$ of the Supporting Information.

3.5.1. Temperature Dependence of Gaussian Bandwidth. The temperature profiles were framed by a broadening mechanism in which strong linear electronic-vibrational coupling prevails. This mechanism gives a Gaussian band shape close to the maximum (eq 1 ):

$$
I(\nu)=A \nu^{3} \exp \left[-\frac{\left(h \nu+h \nu_{\mathrm{m}}\right)^{2}}{\Delta_{\mathrm{s}}^{2}}\right]
$$

where $I(\nu)$ is the intensity of emitted light at the frequency $\nu$ and $h$ Planck's constant. $\nu_{\mathrm{m}}$ is the maximum frequency of the emitted light, related to the equilibrium free energy gap $\left(\Delta G^{0}\right)$ between the ground and excited electronic states and the reorganization free energy ( $E_{s}$, i.e., coupling strength) that accompanies the transition by $h \nu_{\mathrm{m}}=\Delta G^{0}+E_{\mathrm{s}} . \Delta_{\mathrm{s}}$ is the Gaussian bandwidth close to the emission maximum, and $A$ is a constant determined by transition dipole, the instrument setup, and the refractive index of the protein/solvent/particle system.

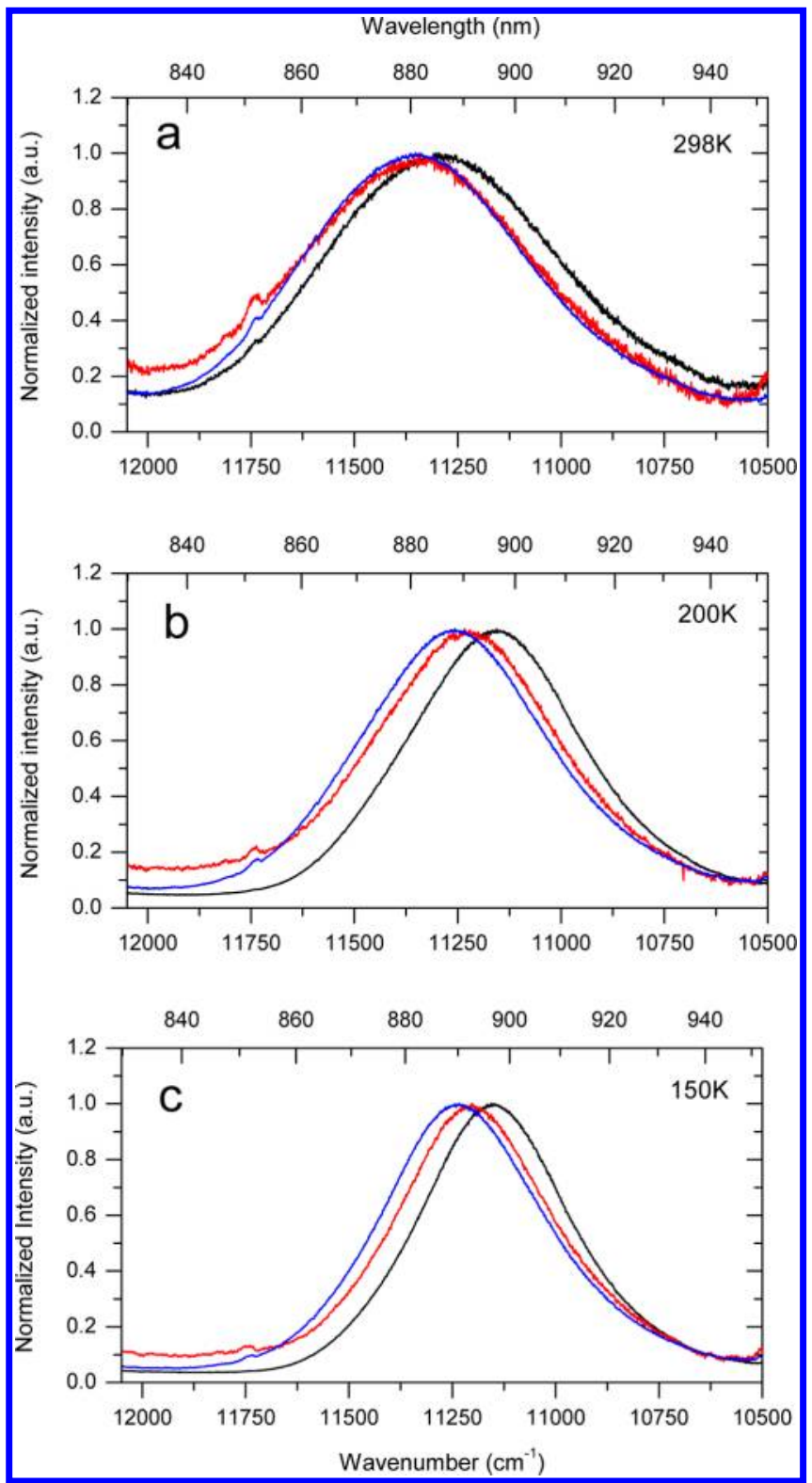

Figure 5. Comparison of steady-state fluorescence emission spectra of free LH2 (black curve), LH2-SBA-sph-l (red curve), and LH2-SBArod (blue) obtained at different temperatures: (a) $298 \mathrm{~K}$, (b) $200 \mathrm{~K}$, and (c) $150 \mathrm{~K}$.

All spectral data below refer to the intensity emission normalized relative to $A \nu^{3}$.

In comparison, the molar absorption coefficient for the absorption band profile corresponding to eq 1 is

$$
\kappa(\nu)=B \nu \exp \left[-\frac{\left(h \nu-h \nu_{m}\right)^{2}}{\Delta_{s}^{2}}\right]
$$

where $B$ is a constant equivalent to $A$ in eq 1 . Eq 1 represents a coarse-grained single transition band shape function. Excited state lifetime (nonradiative transitions, exciton transfer) and multiple transitions can be incorporated as warranted by other band shape forms (e.g., Lorentzian and Voigtian), or by convolution of individual band shape forms. The single Gaussian is, however, adequate for comparison of the LH2 bandshapes in the three environments over the temperature range used. The Gaussian width incorporates the vibrational 

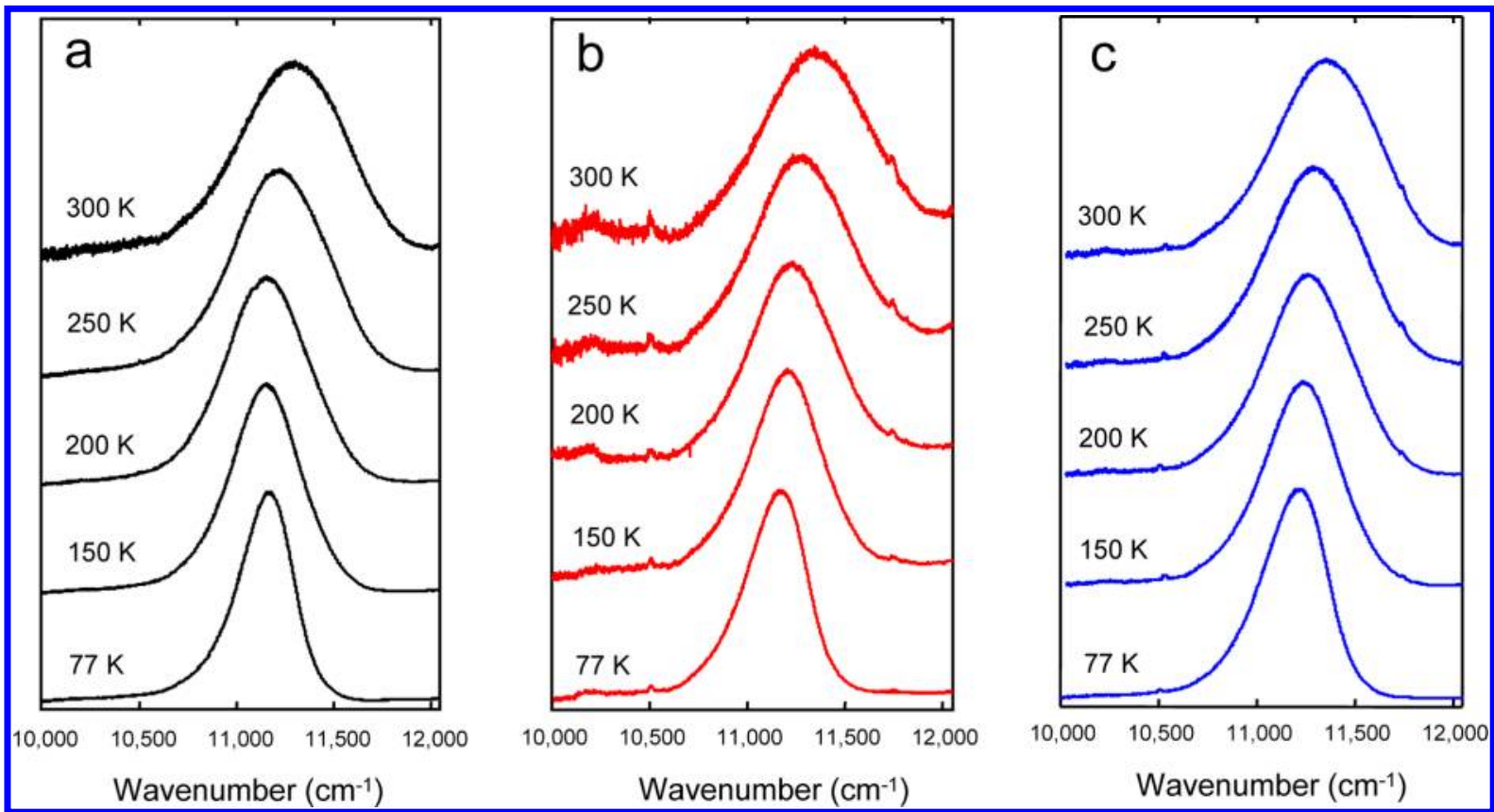

Figure 6. Temperature-dependent fluorescence emission spectra of (a) free LH2 (black curves), (b) LH2-SBA-sph-1 (red curves), and (c) LH2-SBArod (blue curves). The temperatures used in the measurements were in the range of $300-77 \mathrm{~K}$.
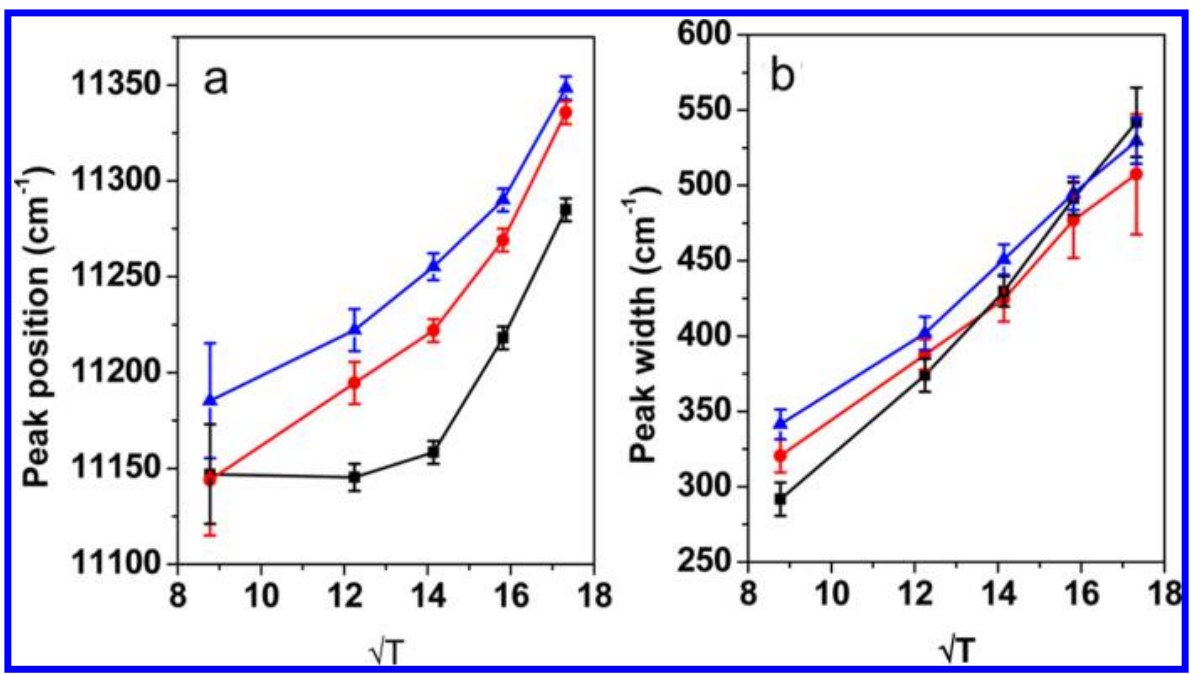

Figure 7. Temperature-dependent peak position (a) and peak width (b) for free LH2 (black), LH2-SBA-sph-1 (red), and LH2-SBA-rod (blue). The solid lines are the fits of the experimental data by a Gaussian function given in eq 1 .

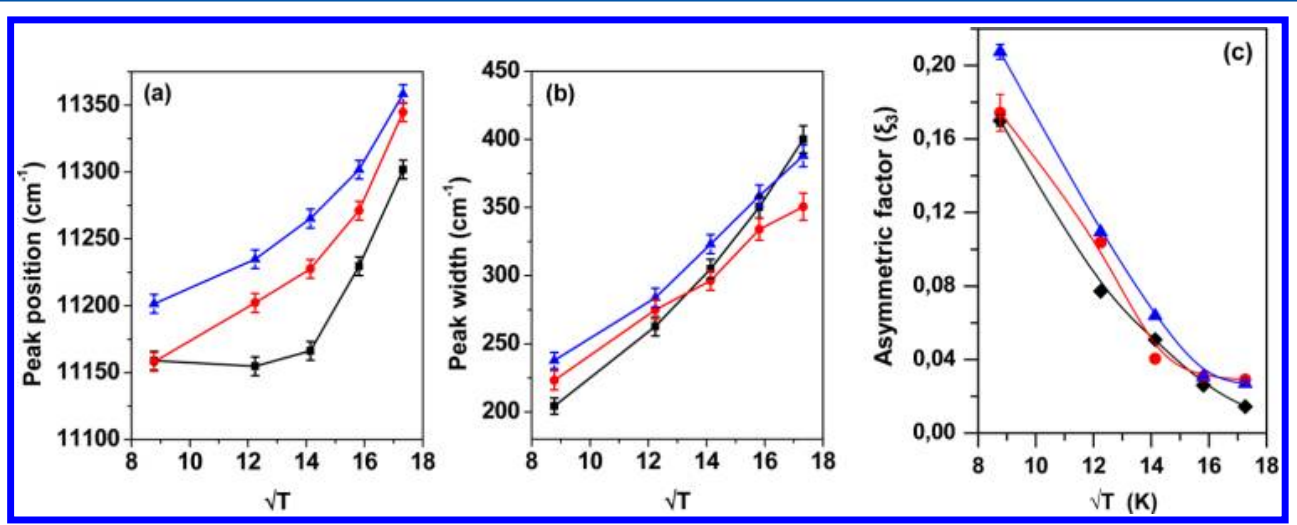

Figure 8. Temperature-dependent peak position (a), peak width (b), and asymmetric factor $\left(\xi_{3}\right)$ (c) for free LH2 (black), LH2-SBA-sph-l (red), and LH2-SBA-rod (blue). The solid lines are the fits of the experimental data by the asymmetric function given in eq 6. 
dispersion of the protein/solvent system. The following bandwidth form is broadly representative ${ }^{55-57}$

$$
\begin{gathered}
\Delta_{\mathrm{s}}=\sqrt{2 k_{\mathrm{B}} T}\left[\int_{0}^{\omega_{\mathrm{c}}} f(\omega) \operatorname{coth}\left(\frac{1}{2} \beta \hbar \omega\right) \mathrm{d} \omega\right]^{1 / 2} ; \\
E_{\mathrm{s}}=\frac{1}{\beta \hbar} \int_{0}^{\omega_{\mathrm{c}}} \frac{\mathrm{d} \omega}{\omega} f(\omega)
\end{gathered}
$$

The function $f(\omega)$ represents the vibrational frequency $(\omega)$ dispersion of the medium, whereas $E_{\mathrm{s}}$ is the total nuclear reorganization free energy that accompanies the transition, cf. above. $\beta=\left(k_{\mathrm{B}} T\right)^{-1}$ where $k_{\mathrm{B}}$ is the Boltzmann's constant and $T$ the temperature, $\hbar=h / 2 \pi$, while $\omega_{\mathrm{c}}$ is a cutoff frequency to account for the transparency regions in the solvent or protein vibrational spectrum. $f(\omega)$ can be represented by suitable spectral forms such as the Debye or resonance forms, ${ }^{58}$ or by the real system spectral density function extracted from spectroscopy. ${ }^{59}$

On the basis of these analyses, we note the following:

(a) $\Delta_{\mathrm{s}}$ in eq 1 reduces to the following simpler forms in the limits of high $\left(\beta \hbar \omega_{\text {eff }} \ll 1\right)$ and low temperatures $\left(\beta \hbar \omega_{\text {eff }}\right.$ $\gg 1)$, respectively.

$$
\Delta_{\mathrm{s}}^{\text {high }}=2 \sqrt{E_{\mathrm{s}} k_{\mathrm{B}} T} ; \Delta_{\mathrm{s}}^{\text {low }}=\sqrt{2 E_{\mathrm{s}} \hbar \omega_{\text {eff }}}
$$

where $\omega_{\text {eff }}$ is an average vibrational frequency of all the nuclear modes. The bandwidth thus follows a $\sqrt{ } T$ dependence at high temperatures and is independent of $T$ at low temperatures. This reflects a transition from nuclear reorganization by thermal activation at high temperature and by nuclear tunneling at low temperature. This transition can, however, be convoluted also with thermal freezing and inhomogeneous broadening.

(b) Significant band narrowing is indeed experimentally observed as the temperature is lowered (Figure 6) and nuclear vibrational excitation is attenuated and increasingly dominated by nuclear tunneling rather than thermal activation.

(c) The $\sqrt{T}$-dependence of the Gaussian bandwidth is shown in part b of Figure 7. The ideal dependence is followed approximately considering the asymmetry features (section 3.5.2) and the possibly composite nature of the transition, cf. above. The T-dependence tails off in the T-range 100-150 K suggesting that low average vibrational frequencies, $\hbar \omega_{\text {eff }} \approx 2 k_{\mathrm{B}} T 150-200$ $\mathrm{cm}^{-1}$ dominate. $E_{\mathrm{s}}$ is in the range $400-500 \mathrm{~cm}^{-1}$ or $50-$ $60 \mathrm{mV}$ representative of coupling to low-frequency protein (or solvent, but cf. below) modes. The coupling strength follows the order LH2 < LH2-SBA-sph-1 < LH2-SBA-rod in most of the temperature range. The transition temperatures also appear slightly different, with those for pore-confined LH2 systematically slightly higher than for free $\mathrm{LH} 2$, i.e., nuclear motion of slightly higher frequencies seem to prevail as LH2 is trapped in the nanopores, in turn indicative of a more rigid protein/ aqueous matrix in the pore confinement than in the free state. Possible implications of this in a biological setting were noted above and are readdressed below.

(d) There is, finally a shift of the band maximum toward lower frequencies as the temperature is lowered (part a of Figure 7). The shift follows roughly the same order as for the bandwidth, LH2 > LH2-SBA-sph-1 > LH2-SBArod. Temperature dependent peak shifts are not inherent in the simplest models for optical electronic transitions. The shifts can be caused by gradual freezing out of part of the vibrational motion (lower polaron trapping energy difference) as the temperature is lowered, or by redistribution among the single chromophores that contribute to the overall fluorescence bands.

3.5.2. Asymmetry Features of Spectral Bands. The Gaussian bandwidth form, eqs 1-3 incorporates coupling to both low-frequency thermally activated classical modes and high-frequency nuclear tunneling modes with increasing prevalence of the latter as the temperature is lowered, and the approximate separation temperature $T \approx 1 / 2 \hbar \omega_{\text {eff }} / k_{\mathrm{B}}$. However, the shape of the band also changes as the temperature is lowered with increasingly slower falloff on the low-frequency side than on the high-frequency side due to more pronounced nuclear tunneling. Mirror effects with slower falloff on the high-frequency side are expected and observed for absorption, with isomorphous free energy correlations of thermal electron transfer reactions in the strongly exothermic free energy range. ${ }^{54,60}$ The high-frequency asymmetry can either be represented by local high-frequency modes enveloped by Gaussian low-frequency environmental distributions, or by continuous environmental distributions corresponding to the infrared tails of the absorption spectra of the aqueous and protein modes. The asymmetry in this representation corresponds to the exponential energy gap law known from nonradiative electronic relaxation in large molecules. $54,55,57,61$

In the continuum representation the high-frequency modes can be represented by a cubic term in the exponent of eq 1 , viz. $^{56,57}$

$$
\begin{aligned}
& I(\nu)=A \nu^{3} \exp \left[-\frac{\left(h \nu+h \nu_{\mathrm{m}}\right)^{2}}{\Delta_{\mathrm{s}}^{2}}-\xi_{3} \frac{\left(h \nu+h \nu_{\mathrm{m}}\right)^{3}}{\Delta_{\mathrm{s}}^{3}}\right] \\
& \xi_{3}=\frac{4}{3} \frac{\hbar^{2}}{\beta} \Delta_{\mathrm{s}}^{-3} \int_{0}^{\omega_{\mathrm{c}}} f(\omega) \omega \mathrm{d} \omega
\end{aligned}
$$

Importantly, $\xi_{3}$ is a positive coefficient. $I(\nu)$ therefore falls off more slowly on the low-frequency side of the maximum than on the high-frequency side. This asymmetry is stronger, the lower the temperature and the higher the vibrational frequencies in $f(\omega)$. As a comparison, the absorption coefficient form corresponding to eq 5 is

$$
\kappa(\nu)=B \nu \exp \left[-\frac{\left(h \nu-h \nu_{\mathrm{m}}\right)^{2}}{\Delta_{\mathrm{s}}^{2}}-\xi_{3} \frac{\left(h \nu-h \nu_{\mathrm{m}}\right)^{3}}{\Delta_{\mathrm{s}}^{3}}\right]
$$

This leads to a slower falloff of the absorption on the highfrequency side than on the low-frequency side of the absorption maximum, in accordance with reported data. ${ }^{56}$

The $\mathrm{T}$-dependence of $\xi_{3}$ reduces to a $\mathrm{T}^{-3 / 2}$-dependence at high temperatures and temperature independence at low temperatures. The band asymmetry is thus expected to increase as the temperature is lowered in the high-temperature limit and to tail off toward a constant value at low temperatures. Figure 8 shows the $\mathrm{T}$-dependence of the asymmetry factor. Whereas a monotonous T-dependence qualitatively following the expectation is apparent, the overall dependence is weaker than ideally expected. Interfering inhomogeneous broadening effects could partly account for this discrepancy.

It is interesting to point out that the trends in the various measured quantities like lifetime, electron-phonon coupling and the temperature-dependent shift of the fluorescence follow 
the same order: LH2, LH2-SBA-sph-1, LH2-SBA-rod. The lifetime and the coupling strength may, in fact, have the same origin - they could be both related to a more rigid packing in the LH2-SBA-rod systems. In case of lifetime, the packing leads to efficient excitation energy transfer and faster quenching, whereas the coupling possibly indicates the rigidity of the system. From the point of view of light harvesting efficiency, the shorter excited state lifetime in the LH2-SBA-rod system would mean more losses and consequently lower efficiency. However, if the origin of the lifetime shortening is close packing, which leads to efficient energy transfer, that would actually mean the system with better transport properties. Furthermore, in case of ambient sunlight conditions, the quenching is expected to be smaller than what is used in experiments. More solid proof of these possibilities needs to await a more systematic study where excitation intensities are varied.

\section{CONCLUSIONS}

The present work addresses an area where nanotechnology is used to study fundamental physicochemical events in specific environments. In this work, an interdisciplinary approach that combines the design and synthesis of mesoporous materials and various biophysical methods was employed. Rational design and controlled synthesis have yielded mesoporous silicas with the desired particle shapes and pore sizes. $\mathrm{LH} 2$ was targeted due to its intrinsic fluorescence sensitivity and general importance in photosynthesis.

The differences between the LH2 steady-state fluorescence spectra in the free and pore-confined environments are systematic. Based on a simplified view of a single (although coarse-grained) electronic transition and strong electronicvibrational coupling as the prevailing broadening mechanisms, the analysis of the temperature-dependent bandshapes and bandwidths has offered interesting insight. Vibrational dispersion of the protein and solvent modes including both lowand high-frequency ranges are further incorporated. This approach has been used successfully in previous analysis of both solvatochromic charge transfer bands of large organic molecules (i.e., betaines) ${ }^{56}$ and in modified form also for symmetry-forbidden $\mathrm{d}$-d transitions in transition metal complexes. ${ }^{62}$ Our analysis shows that the band shape patterns follow broadly expected temperature dependence for the limit of strong electronic-vibrational coupling with dominating vibrational frequencies in the range of $150-200 \mathrm{~cm}^{-1}$. Beginning of quantum mechanical freezing (nuclear tunneling) at the lowest temperatures $(\rightarrow 77 \mathrm{~K})$ could further be distinguished from the temperature-dependent variation of the bandwidth.

Electronic-vibrational coupling differences between the free and pore-confined LH2 environments could finally be distinguished based on the band shape analysis. The bandwidth pointed to slightly larger coupling strength and effective vibrational frequencies in the pore confinement compared with freely dissolved LH2. These observations are a clear indication of a more rigid environmental matrix surrounding LH2 molecules.

\section{ASSOCIATED CONTENT}

\section{S Supporting Information}

Experimental detail and supporting data for synthesis and characterization of mesoporous silicas, ellipsometric data, and photographs and schematic illustrations of the experimental setups for wide-field fluorescence microscopy and low-temperature fluorescence spectroscopy. This material is available free of charge via the Internet at http://pubs.acs.org.

\section{AUTHOR INFORMATION}

\section{Corresponding Author}

*E-mail: cq@kemi.dtu.dk (Q.C.), tonu.pullerits@chemphys.lu. se (T.P.).

\section{Author Contributions}

${ }^{\dagger}$ These authors contributed equally to this work.

Notes

The authors declare no competing financial interest.

\section{ACKNOWLEDGMENTS}

This work was financially supported by the Lundbeck Foundation (to Q.C., Grant No. R49-A5331) and the Danish Research Council for Technology and Production Sciences (to J.U. and Q.C., Project No. 274-07-0272,) in Denmark; and by KWA Foundation and STEM (to T.P.) in Sweden. S.T. acknowledges financial support from the Swedish Institute and Higher Education Commission for Ph.D study. We thank Prof. Richard Cogdell for providing LH2 samples, Dr. Ivan Scheblykin for valuable discussions, the researchers at the Center of Electron Nanoscopy at DTU for their assistance in the SEM and TEM measurements, Helge Kildahl Rasmussen at DTU Physics for help in the XRD experiments, Robert Madsen at DTU Chemistry for help with the facilities for chemical synthesis, Rasmus Fehrmann and co-workers at DTU Chemistry for help in the measurements of the pore size distribution, and Marie Wahlgren at Lund University for help in the ellipsometery experiments.

\section{REFERENCES}

(1) Berg, J. M.; Tymoczko, J. L.; Stryer, L. Biochemistry: International Ed., W. H. Freeman, 2006.

(2) Kalay, Z. Fundamental and Functional Aspects of Mesoscopic Architectures with Examples in Physics, Cell Biology, and Chemistry. Crit. Rev. Biochem. Mol. Biol. 2011, 46, 310-326.

(3) Hartmann, M.; and Jung, D.. Immobilization of Proteins and Enzymes, Mesoporous Supports. In Encyclopedia of Industrial Biotechnology: Bioprocess, Bioseparation, and Cell Technology, Vol. 7, pp 1-30; New York: John Wiley \& Sons; 2009.

(4) Huang, Y.-W.; Lai, Y.-C.; Tsai, C.-J.; Chiang, Y.-W. Mesopores Provide an Amorphous State Suitable for Studying Biomolecular Structures at Cryogenic Temperatures. Proc. Natl. Acad. Sci. U.S.A. 2011, 108, 14145-14150.

(5) Kresge, C. T.; Leonowicz, M. E.; Roth, W. J.; Vartuli, J. C.; Beck, J. S. Ordered Mesoporous Molecular-Sieves Synthesized by a LiquidCrystal Template Mechanism. Nature 1992, 359, 710-712.

(6) Wan, Y.; Zhao, D. On the Controllable Soft-templating Approach to Mesoporous Silicates. Chem. Rev. 2007, 107, 2821-2860.

(7) Coti, K. K.; Belowwich, M. E.; Liong, M.; Ambrogio, M. W.; Lau, Y. A.; Khatib, H. A.; Zink, J. I.; Khashab, N. M.; Stoddart, J. F. Mechanised Nanoparticles for Drug Delivery. Nanoscale 2009, 1, 1639.

(8) Che, S.; Garcia-Bennett, A. E.; Yokoi, T.; Sakamoto, K.; Kunieda, H.; Terasaki, O.; Tatsumi, T. A. Novel Anionic Surfactant Templating Route for Synthesizing Mesoporous Silica with Unique Structure. Nat. Mater. 2003, 2, 801-806.

(9) Zhao, D.; Feng, J.; Huo, Q.; Melosh, N.; Fredrickson, H. G.; Chmelka, F. B.; Stucky, D. G. Triblock Copolymer Syntheses of Mesoporous Silica with Periodic 50 to 300 Angstrom Pores. Science 1998, 279, 548-552.

(10) Schmidt-Winkel, P.; Lukens, W. W., Jr.; Zhao, D.; Yang, P.; Chmelka, B. F.; Stucky, G. D. Mesocellular Siliceous Foams with 
Uniformly Sized Cells and Windows. J. Am. Chem. Soc. 1999, 121, 254-255.

(11) Díaz, J. F.; Balkus, K. J., Jr. Enzyme Immobilization in MCM-41 Molecular Sieve. J. Mol. Catal. B: Enzym. 1996, 2, 115-126.

(12) Tran, D. N.; Balkus, K. J., Jr. Perspective of Recent Progress in Immobilization of Enzymes. ACS Catalysis 2011, 1, 956-968.

(13) Ikemoto, H.; Chi, Q.; Ulstrup, J. Stability and Catalytic Kinetics of Horseradish Peroxidase Confined in Nanoporous SBA-15. J. Phys. Chem. C 2010, 114, 16174-16180.

(14) Slowing, I.; Trewyn, B. G.; Lin, V. S. Y. Mesoporous Silica Nanoparticles for Intracellular Delivery of Membrane-impermeable Proteins. J. Am. Chem. Soc. 2007, 129, 8845-8849.

(15) Shimomura, T.; Itoh, T.; Sumiya, T.; Mizukami, F.; Ono, M. Electrochemical Biosensor for the Detection of Formaldehyde Based on Enzyme Immobilization in Mesoporous Silica Materials. Sens. Actuators, B 2008, 135, 268-275.

(16) Savino, R.; Casadonte, F.; Terracciano, R. In Mesopore Protein Digestion: A New Forthcoming Strategy in Proteomics. Molecules. 2011, 16, 5938-5962.

(17) Ravindra, R.; Zhao, S.; Gies, H.; Winter, R. Protein Encapsulation in Mesoporous Silicate: The Effects of Confinement on Protein Stability, Hydration, and Volumetric Properties. J. Am. Chem. Soc. 2004, 126, 12224-12225.

(18) Itoh, T.; Yano, K.; Inada, Y.; Fukushima, Y. Photostabilized Chlorophyll a in Mesoporous Silica: Adsorption Properties and Photoreduction Activity of Chlorophyll a. J. Am. Chem. Soc. 2002, 124, 13437-13441.

(19) Itoh, T.; Yano, K.; Kajino, T.; Itoh, S.; Shibata, Y.; Mino, H.; Miyamoto, R.; Inada, Y.; Iwai, S.; Fukushima, Y. Nanoscale Organization of Chlorophyll a in Mesoporous Silica: Efficient Energy Transfer and Stabilized Charge Separation as in Natural Photosynthesis. J. Phys. Chem. B. 2004, 108, 13683-13687.

(20) Oda, I.; Hirata, K.; Watanabe, S.; Shibata, Y.; Kajino, T.; Fukushima, Y.; Iwai, S.; Itoh, S. Function of Membrane Protein in Silica Nanopores: Incorporation of Photosynthetic Light-harvesting Protein LH2 into FSM. J. Phys. Chem. B 2006, 110, 1114-1120.

(21) Oda, I.; Iwaki, M.; Fujita, D.; Tsutsui, Y.; Ishizawa, S.; Dewa, M.; Nango, M.; Kajino, T.; Fukushima, Y.; Itoh, S. Photosynthetic Electron Transfer from Reaction Center Pigment-Protein Complex in Silica Nanopores. Langmuir 2010, 26, 13399-13406.

(22) Hu, X.; Ritz, T.; Damjanovic, A.; Autenrieth, F.; Schulten, K. Photosynthetic Apparatus of Purple Bacteria. Q. Rev. Biophys. 2002, 35, $1-62$.

(23) Cogdell, R. J.; Gall, A.; Köhler, J. The Architecture and Function of the Light-harvesting Apparatus of Purple Bacteria: from Single Molecules to in vivo Membranes. Q. Rev. Biophys. 2006, 39, 227-234.

(24) Voet, D.; Voet, J. G. Biochemisty, $2^{\text {nd }}$ ed.; John Wiley \& Sons, Inc., 1995.

(25) Pflock, T. J.; Oellerich, S.; Southall, J.; Cogdell, R. J.; Ullman, G. M.; Köhler, J. The Electronically Excited States of LH2 Complexes from Rhodopseudomonas acidophila Strain 10050 Studied by TimeResolved Spectroscopy and Dynamic Monte Carlo Simulations. I. Isolated, Non-Interacting LH2 Complexes. J. Phys. Chem. B. 2011, 115, 8813-8820.

(26) Pflock, T. J.; Oellerich, S.; Southall, J.; Cogdell, R. J.; Ullman, G. M.; Köhler, J. The Electronically Excited States of LH2 Complexes from Rhodopseudomonas acidophila Strain 10050 Studied by TimeResolved Spectroscopy and Dynamic Monte Carlo Simulations. II. Homo-Arrays of LH2 Complexes Reconstituted Into Phospholipid Model Membranes. J. Phys. Chem. B 2011, 115, 8821-8831.

(27) Tubasum, S.; Cogdell, R. J.; Scheblykin, I. G.; Pullerits, T. Excitation-Emission Polarization Spectroscopy of Single Light Harvesting Complexes. J. Phys. Chem. B 2011, 115, 4963-4970.

(28) Sundström, V.; Pullerits, T.; van Grondelle, R. Photosynthetic Light-harvesting: Reconciling Dynamics and Structure of Purple Bacterial LH2 Reveals Function of Photosynthetic Unit. J. Phys. Chem. B 1999, 103, 2327-2346.
(29) Pullerits, T.; Sundström, V. Photosynthetic Light-harvesting Pigment-protein Complexes: Toward Understanding How and Why. Acc. Chem. Res. 1996, 29, 381-389.

(30) Peterman, E. J. G.; Pullerits, T.; van Grondelle, R.; van Amerongen, H. Electron-phonon Coupling and Vibronic Fine Structure of Light-harvesting Complex II of Green Plants: Temperature Dependent Absorption and High-resolution Fluorescence Spectroscopy. J. Phys. Chem. B 1997, 101, 4448-4457.

(31) Pullerits, T.; Hess, S.; Herek, J. L.; Sundström, V. Temperature Dependence of Excitation Transfer in LH2 of Rhodobacter Sphaeroides. J. Phys. Chem. B 1997, 101, 10560-10567.

(32) Schubert, A.; Stenstam, A.; Beenken, W. J. D.; Herek, J. L.; Cogdell, R.; Pullerits, T.; Sundström, V. In vitro Self-assembly of the Light Harvesting Pigment-protein LH2 Revealed by Ultrafast Spectroscopy and Electron Microscopy. Biophys. J. 2004, 86, 23632373.

(33) Polivka, T.; Pullerits, T.; Frank, H. A.; Cogdell, R. J.; Sundström, V. Ultrafast Formation of a Carotenoid Radical in LH2 Antenna Complexes of Purple Bacteria. J. Phys. Chem. B 2004, 108, 1539815407.

(34) Christensson, N.; Milota, F.; Nemeth, A.; Sperling, J.; Kauffmann, H. F.; Pullerits, T.; Hauer, J. Two-Dimensional Electronic Spectroscopy of beta-Carotene. J. Phys. Chem. B 2009, 113, 1640916419.

(35) Brüggemann, B.; Christensson, N.; Pullerits, T. Temperature Dependent Exciton-exciton Annihilation in the LH2 Antenna Complex. Chem. Phys. 2009, 357, 140-143.

(36) Hawthornthwaite, A. M.; Cogdell, R. J. In Chlorophylls: Bateriochlorophyll Binding Proteins; Scheer, H., Ed.; CRC Press: Boca Raton, FL, 1991, pp 493-528.

(37) Cao, L.; Man, T.; Kruk, M. Synthesis of Ultra-Large-Pore SBA15 Silica with Two-Dimensional Hexagonal Structure Using Triisopropylbenzene as Micelle Expander. Chem. Mater. 2009, 21, $1144-1153$

(38) Gartmann, N.; Brühwiler, D. Controlling and Imaging the Functional-Group Distribution on Mesoporous Silica. Angew. Chem., Int. Ed. 2009, 48, 6354-6356.

(39) Wang, L.; Qi, T.; Zhang, Y.; Chu, J. L. Morphosynthesis Route to Large-pore SBA-15 Microspheres. Microporous Mesoporous Mater. 2006, 91, 156-160.

(40) Lakowicz, J. R. Principles of Fluorescence Spectroscopy, $3^{\text {rd }}$ ed.; Springer, 2006.

(41) Angulo, G.; Grampp, G.; Rosspeintner, A. Recalling the Appropriate Representation of Electronic Spectra. Spectrochim. Acta, Part A 2006, 65, 727-731.

(42) Wahlgren, M.; Arnebrant, T. Adsorption of Beta-lactoglobulin onto Silica, Methylated Silica, and Polysulfone. J. Colloid Interface Sci. 1990, 136, 259-265.

(43) De Feijter, J. A.; Benjamins, J.; Veer, F. A. Ellipsometry as a Tool to Study Adsorption Behavior of Synthetic Biopolymers at AirWater Interfaces. Biopolymers 1978, 17, 1759-1772.

(44) Ravikovitch, P. I.; Neimark, A. V. Characterization of Micro- and Mesoporosity in SBA-15 materials From Adsorption Data by the NLDFT Method. J. Phys. Chem. B 2001, 105, 6817-6823.

(45) Brunauer, S.; Emmett, P. H.; Teller, E. Adsorption of Gases in Multimolecular Layers. J. Am. Chem. Soc. 1938, 60, 309-319.

(46) Lukens, W. W.; Schmidt-Winkel, P.; Zhao, D. Y.; Feng, J.; Stucky, G. D. Evaluating Pore Sizes in Mesoporous Materials: A Simplified Standard Adsorption Method and a Simplified Broekhoff-de Boer Method. Langmuir 1999, 15, 5403-5409.

(47) Papiz, M. Z.; Prince, S. M.; Howard, T.; Cogdell, R. J.; Isaacs, N. W. The Structure and Thermal Motion of the B800-850 LH2

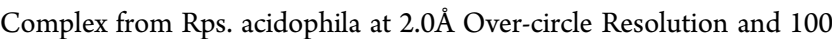
K: New Structural Features and Functionally Relevant Motions. J. Mol. Biol. 2003, 326, 1523-1538.

(48) Macpherson, A.; Arellano, J. B.; Fraser, N. J.; Cogdell, R. J.; Gillbro, T. Efficient Energy Transfer from the Carotenoid S-2 State in a Photosynthetic Light-harvesting Complex. Biophys. J. 2001, 80, 923930. 
(49) Kennis, J. T. M.; Streltsov, A. M.; Vulto, S. I. E. T.; Aartsma, J.; Nozawa, T. Z.; Amesz, J. Femtosecond Dynamics in Isolated LH2 Complexes of Various Species of Purple Bacteria. J. Phys. Chem. B 1997, 101, 7827-7834.

(50) Stutz, H. Protein Attachment onto Silica Surfaces - a Survey of Molecular Fundamentals, Resulting Effects and Novel Preventive Strategies in CE. Electrophoresis 2009, 30, 2032-2061.

(51) Monger, T. G.; Parson, W. W. Singlet-triplet Fusion in Rhodopseudomonas-sphaeroides Chromatophores-Probe of Oganization of Photosynthetic Apparatus. Biochim. Biophys. Acta 1977, 460, 393-407.

(52) Pflock, T.; Dezi, M.; Venturoli, G.; Cogdell, R. J.; Oellerich, S.; Köhler, J.; Oellerich, S. Comparison of the Fluorescence Kinetics of Detergent-solubilized and Membrane-reconstituted LH2 Complexes from Rps. acidophila and Rb. Sphaeroides. Photosynth. Res. 2008, 95, 291-298.

(53) Bartl, M. H.; Boettcher, S. W.; Frindell, K. L.; Stucky, G. D. 3-D Molecular Assembly of Function in Titania-based Composite Material Systems. Acc. Chem. Res. 2005, 38, 263-271.

(54) Ulstrup, J.; Jortner, J. Effect of Intermolecular Quantum Modes on Free-Energy Relationships for Electron-transfer Reactions. J. Chem. Phys. 1975, 63, 4358-4368.

(55) Kuznetsov, A. M.; Ulstrup, J. Electron Transfer in Chemistry and Biology: An Introduction to the Theory; Wiley, 1999.

(56) Kjaer, A. M.; Ulstrup, J. Solvent Bandwidth Dependence and Band Asymmetry Features of Charge-transfer Transitions in $\mathrm{N}$ Pyridinium Phenolates. J. Am. Chem. Soc. 1987, 109, 1934-1942.

(57) Itskovitch, E. M.; Ulstrup, J.; Vorotyntsev, M. A. In The Chemical Physics of Solvation, Part B; Dogonadze, R. R., Kálmán, E., Kornyshev, A. A., Ulstrup, J., Eds.; Elsevier: Amsterdam, 1986, pp 223-310.

(58) Fröhlich, H. A. Theory of Dielectrics; 2nd. ed.; Clarendon: Oxford, 1958.

(59) Pullerits, T.; van Mourik, F.; Monshouwer, R.; van Grondelle, R. Electron-Phonon Coupling in the B820 Subunit Form of LH1 Studied by Temperature Dependence of Optical Spectra. J. Luminesc. 1994, 58, $168-171$.

(60) Gundlach, L.; Willig, F. Ultrafast Photoinduced Electron Transfer at Electrodes: The General Case of a Heterogeneous Electron-transfer Reaction. Chem. Phys. Chem. 2012, 13, 2877-2881.

(61) Fong, F. K. Theory of Molecular Relaxation; Wiley: New York, 1975.

(62) Kristjánsson, I.; Ulstrup, J. Ultraviolet and Visible-Light Absorption of Solvated Molecules and Charge-Transfer Complexes. Chem. Scripta 1985, 25, 49-57. 